Please quote as: Bitzer, P.; Weiß, F. \& Leimeister, J. M. (2013): Towards a Reference Model for a Productivity-optimized Delivery of Technology Mediated Learing Services. In: Eighth International Conference on Design Science Research in Information Systems and Technology (DESRIST), Helsinki, Finland. 


\title{
Towards a Reference Model for a Productivity optimized delivery of Technology Mediated Learning Services
}

\begin{abstract}
Technology mediated learning services (TMLS) play an important role for software on-the-job-training due to increasing cost pressure for on-the-job-training and increasing demand for mobile learning solutions. As there is no structured approach to systematically deliver productive TMLS this research study creates a holistic reference model of a productivity-optimized TMLS delivery process. This productivity-optimized model focuses on the efficient use of resources at a constant or increasing TMLS outcome by a set of process models and design guidelines for TMLS providers. It is developed within a design research setting and derives existing knowledge from the literature and three in-depth-case studies with training providers for software applications. More precisely, requirements for a productive delivery of TMLS were identified, collected and abstracted. Consequently, we build a reference model that supports the following activities of technology oriented learning: training preparation, training delivery within the classroom, training delivery through internet and training evaluation under consideration of various stakeholders, such as the TMLS provider, trainer, TMLS participant and the participants company. We use expert interviews to evaluate the reference model against the defined design goals and for perceived usefulness, ease of use and overall utility.
\end{abstract}

This work-in-progress-paper is to the best of our knowledge the first that provides a productivity-optimized reference model for the delivery of technology mediated learning services. It represents a formalization of a problem domain comprising process models and design guidelines for the systematic delivery of productive TMLS. 


\section{Introduction}

Arthur et al. (2003) identified the influence of technology in all learning scenarios referred to as technology-mediated learning as a major trend in education. Technology mediated learning services (TMLS) will gain more importance and will lead to innovative, more individual, more resource-preserving ways of learning, e.g. micro-learning at the workplace or locationindependent cloud-based learning (MBB 2011). According to Wainhouse Research (2007) the global market value of TML is expected to increase from $\$ 802.8$ million in 2007 to $\$ 1.5$ billion in 2011, for a compounded annual growth rate of $13 \%$. Thereby, software trainings have the biggest share of trainings conducted in Germany (AES 2010).

Despite its many advantages, TMLS incite several fundamental challenges: First and foremost, it still remains challenging for TMLS designers to figure out, what the best combination of synchronous and asynchronous learning elements is for a specific TMLS participant groups and contents (Gupta and Bostrom 2009; Gupta et al. 2008). The variety and heterogeneity of research results lead to an inconclusive database for a systematic productivity-optimized TMLS provision which fosters resource-saving aspects of IT use with potential learning success gains (Gupta et al. 2008; Lehtinen et al. 1999). The lack of transferable insights can be explained since many studies have used input-output research designs that ignore critical aspects of the learning method and process (Gupta and Bostrom 2009). Consequently, without the consideration of the learning process perspective, including learning methods, the research done so far is not adequate to face the increasing use of technology in TMLS, and still is not sufficient for the dynamic development in practice (Alavi and Leidner 2001; Sasidharan and Santhanam 2006). Therefore, a comprehensive view on TMLS is needed, which includes not only the input and output perspective but additionally the process perspective on TMLS. From a providers perspective, this is an important condition to systematically provide TMLS, sup- 
porting a productive respectively cost-efficient service delivery in terms of providers input and providers respectively customers output (Grönroos and Ojasalo 2004; Parasuraman 2002). The objective of this study is to develop a reference model that enables training providers for software applications ("software training providers") to deliver productive TMLS, i.e. with an efficient use of input factors during the provision process at a constant or improved output level for their customers. Provider and customer requirements are collected and a theory and practice based reference model for productivity-optimized TMLS delivery is derived.

Therefore, a reference model is built, comprising productivity-oriented TMLS delivery processes. The processes are developed through literature and case study analysis.

Accordingly, this paper aims to answer the following research question: How must a reference model be conceptualized, in order to support the productive provision of TMLS in the context of technology mediated trainings teaching software application use.

In order to achieve our desired goal, the research in this paper is structured as follows in the ensuing sections. The related work, research method, case set up and respective information systems are introduced. Subsequently, the results are elaborated and discussed. Lastly, conclusions drawn on our part are summarized.

\section{FOUNDATION AND RELATED WORK}

The term technology mediated learning services has many variations and is often a combination of the following learning modes: web-based or computer-based, asynchronous or synchronous, instructor-led or self-paced, individual-based or team-based (Gupta and Bostrom 2009). More precisely, the goal of TMLS is to integrate the strengths of synchronous (face-toface) and asynchronous (internet-based) learning activities (Garrison and Kanuka 2004). According to this definition, we define technology mediated learning as teaching and learning 
activities which are conducted by means of traditional face-to-face training in combination with internet-based training activities.

Since the goal of this study is to develop a productivity-optimized reference model, we have to introduce the service productivity concept: In contrast to production productivity, service productivity has to consider not only quantitative aspects (e.g. number of participants) but also qualitative aspects (e.g. learning success) (McLaughlin and Coffey 1990). This implies that, although the efficient use of resources is in the focus of this study, i.e. the lowest possible use of resources such as working hours, also the effectiveness, i.e. the TMLS such as learning success or participant satisfaction, has to be considered for a productive TMLS delivery.

The challenge of a productive delivery of technology mediated learning services remains to deliver the right content in the right format to the right people at the right time, since learning requirements and preferences of each learner tend to be different (Singh 2003). The existing research shows various design recommendations for the efficient and effective delivery of TMLS in the context of software trainings (Gupta et al. 2008). Nevertheless there is no comprehensive approach to systematically deliver productive TMLS (Gupta and Bostrom 2009), integrating requirements like e.g. a holistic TMLS process perspective (Compeau and Higgins 1995; Gupta and Bostrom 2009). Therefore, this study aims to develop a reference model incorporating findings from theory and practice, focusing on dimensions, roles, activities and processes.

\section{RESEARCH METHODOLOGY}

Despite the high need for supporting software training providers in the design of productivityoptimized TMLS, no corresponding reference model can be found in the literature. To close this gap, by the use of design science research, a process model and success factors for productive TMLS implementation are developed. According to Hevner et al. (2004) a model uses 
constructs - language for the definition and communication of problems and solutions (Schön $1984)$ - to present a real world design problem and to develop a concrete solution (Simon 1996). More concrete, a reference model is developed providing "best-practice processes for a domain, which can be adapted to aid companies in designing and operating their business (Becker and Schütte 1996 p.36)". Following this definition, reference models represent knowledge about a specific domain - in our case the knowledge to identify the business value of IT applications. The constructed model is set up to assist designers to reduce the time necessary to develop TMLS, reduce the development effort, incorporate new ideas best practices and minimize the risk of failure (Ahlemann and Riempp 2008).

As described in Hevner et al. (2004) design science focuses on "building and evaluation of artifacts designed to meet the identified business needs (p. 79-80)". To build artifacts by design research Takeda et al. (1990) propose a five-phased approach starting with creating awareness of the problem. In our study, following Ahlemann and Riempp (2008), the problem domain was formulated through literature review. In addition to enrich the requirements respectively design goals found in literature three case studies with major German software training providers were conducted. Within the case studies 13 expert interviews and provided documents were analyzed and a training session was observed (Yin 2009). In accordance to Takeda et al. (1990) in the next steps, based on the design goals derived, the artifact was developed. Insights complied from literature and workshops with TMLS providers and trainers were used to derive best practices. In a next step - to be conducted - the reference model will be evaluated (Takeda et al. 1990). Conclusions drawn from the evaluation will be used to adapt and optimize the model (Hevner et al. 2004). 


\section{RESEARCH RESULTS}

On the foundation of the three case studies (deductive) and the design requirements from the literature (inductive) a first version of the reference model was built. The following design goals, as shown in table 1, were derived and used for the model creation:

Table 1: Design goals for a reference model for a productivity-optimized TMLS delivery

\begin{tabular}{|c|c|c|c|}
\hline Design goal & Description & $\begin{array}{l}\text { Body of litera- } \\
\text { ture }\end{array}$ & $\begin{array}{l}\text { Derived } \\
\text { from the } \\
\text { case studies }\end{array}$ \\
\hline $\begin{array}{l}\text { Consideration of } \\
\text { TMLS-productivity } \\
\text { requirements }\end{array}$ & $\begin{array}{l}\text { Resource-optimized TMLS deli- } \\
\text { very is the goal, evaluated by quan- } \\
\text { titative and qualitative input, } \\
\text { process and output indicators }\end{array}$ & $\begin{array}{l}\text { (Bitzer et al. } \\
2011 ; \\
\text { McLaughlin and } \\
\text { Coffey 1990) }\end{array}$ & $\mathbf{x}$ \\
\hline $\begin{array}{l}\text { Holistic trainings } \\
\text { process orientation }\end{array}$ & $\begin{array}{l}\text { The development of an end-user } \\
\text { training program involves three } \\
\text { consecutive distinct phases: initia- } \\
\text { tion, formal training \& learning as } \\
\text { well as post training }\end{array}$ & $\begin{array}{l}\text { Compeau and } \\
\text { Higgins } 1995\end{array}$ & \\
\hline $\begin{array}{l}\text { Integration of multi- } \\
\text { dimensional stake- } \\
\text { holders }\end{array}$ & $\begin{array}{l}\text { The following stakeholders are } \\
\text { considered: 1.) training provider, } \\
\text { 2.) trainer, 3.) training participant } \\
\text { and 4.) customer, i.e. the trainings' } \\
\text { participant company }\end{array}$ & $\begin{array}{l}\text { (Bitzer et al. } \\
2010 ; \\
\text { Fitzsimmons and } \\
\text { Fitzsimmons } \\
\text { 2006) }\end{array}$ & $\mathbf{x}$ \\
\hline $\begin{array}{l}\text { Learning goal } \\
\text { oriented service deli- } \\
\text { very }\end{array}$ & $\begin{array}{l}\text { The implementation of a training } \\
\text { needs assessment is considered as a } \\
\text { crucial initial step to training and is } \\
\text { substantially influencing the overall } \\
\text { effectiveness of training programs } \\
\text { and serves as a fundament for de- } \\
\text { sign, development, delivery and } \\
\text { evaluation of training. }\end{array}$ & $\begin{array}{l}\text { (Arthur Jr et al. } \\
\text { 2003) }\end{array}$ & \\
\hline $\begin{array}{l}\text { Integration of confi- } \\
\text { gurable service ele- } \\
\text { ments }\end{array}$ & $\begin{array}{l}\text { Due to the great variety in customer } \\
\text { demands and learning content, the } \\
\text { integration of configurable service } \\
\text { elements is necessary. }\end{array}$ & & $\mathbf{x}$ \\
\hline $\begin{array}{l}\text { Separation between } \\
\text { process and learning } \\
\text { units }\end{array}$ & $\begin{array}{l}\text { The variability of service elements } \\
\text { requires s separation between the } \\
\text { process dimension, describing ac- } \\
\text { tivities to support the actual learn- } \\
\text { ing units, i.e. a combination of } \\
\text { learning methods. }\end{array}$ & $\begin{array}{l}\text { (Gupta and } \\
\text { Bostrom 2009) }\end{array}$ & \\
\hline
\end{tabular}




\section{The Reference Model Architecture}

Various authors propose to develop reference model architectures to provide an overview of complex reference models (Ahlemann and Riempp 2008; Meise 2001; Schlagheck 2000). Thereby, the overall problem domain can be decomposed into smaller manageable units to provide a high-level overview of the reference model (Ahlemann and Riempp 2008).

The reference model architecture consists of eight layers, each of them comprising activities and modeled processes, using the Business Process Modeling Notation (BPMN), which were developed based on the derived design goals. Due to page limitations, only excerpts of the reference model are described in the following.

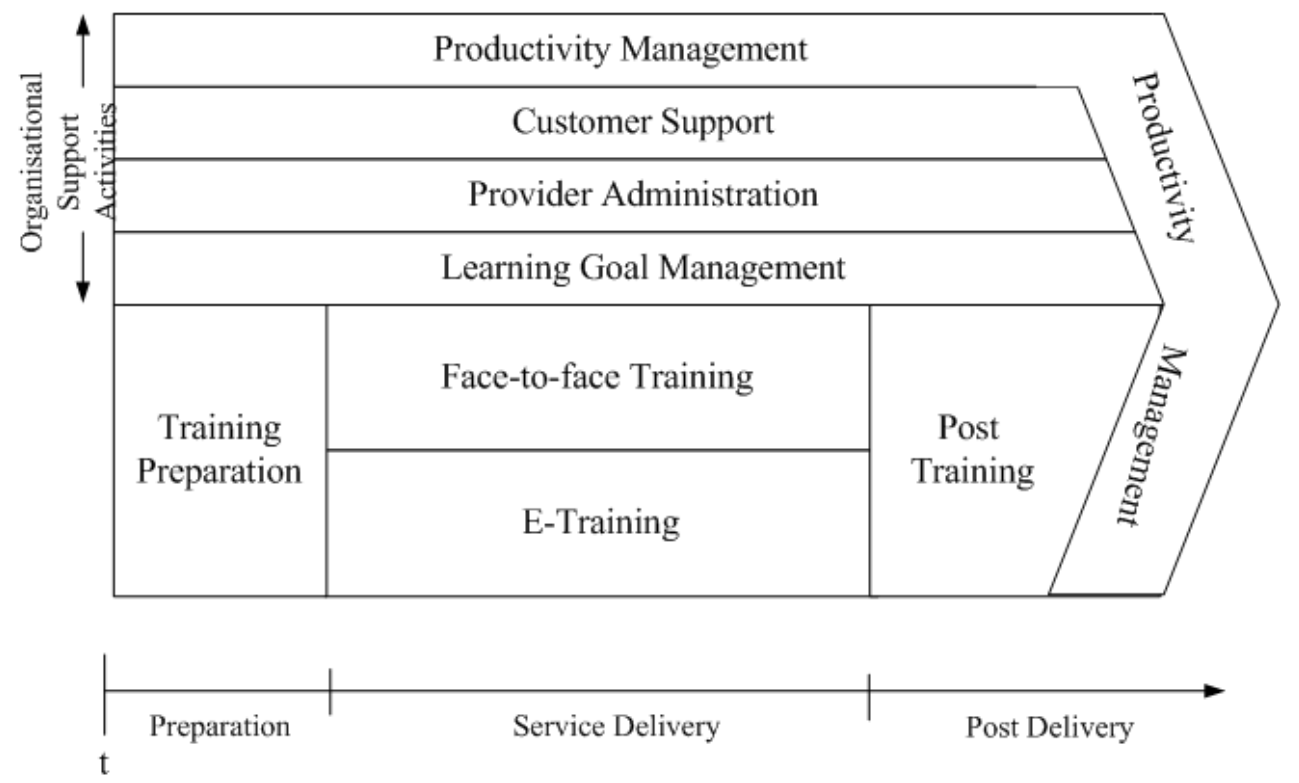

Fig. 1: Reference Model Architecture

Overall, the reference model comprises processes for every presented layer in order to deliver productivity-optimized TMLS. Thereby findings from service science, IS research, education and business science are integrated within the reference model. The processes which were 
modeled using the Business Process Management Notation (BPMN) include processes as well as productivity guidelines for the different layers describing actions which support a productive TMLS delivery in the context of software-trainings ${ }^{1}$. The reference model includes support activities as well as the service delivery activities. The support activities comprise the following layers: Within the productivity management layer measures for the productivity assessment are described, including a productivity measurement instrument, activities for the provider-specific customizing and measures to increase productivity. In the customer support layer activities for the support of the participants' company /companies (i.e. the customer(s)) are described, e.g. activities to integrate the learning content into the participants' working environment. The provider administration layer comprises activities for the organizational support of the participants and trainers before, during and after the service delivery process. Within the learning goal management layer activities concerning the identification, integration and accomplishment of learning goals are described.

The TMLS delivery process is separated into training preparation, including activities to train content before the actual training begins and to deliver additional, training related information, e.g. information about the training structure. The service delivery is further separated into face-to-face activities, comprising activities which are conducted within the training facilities, and E-Training activities, comprising activities which are computer-based and location-independent. Last, after training activities are presented within the Post Training layer. To illustrate the results, an example process, showing an excerpt of the face-to-face-trainingprocess, is shown in figure 2 .

\footnotetext{
${ }^{1}$ In the following, the term "activities" describes processes as well as supporting measures
} 


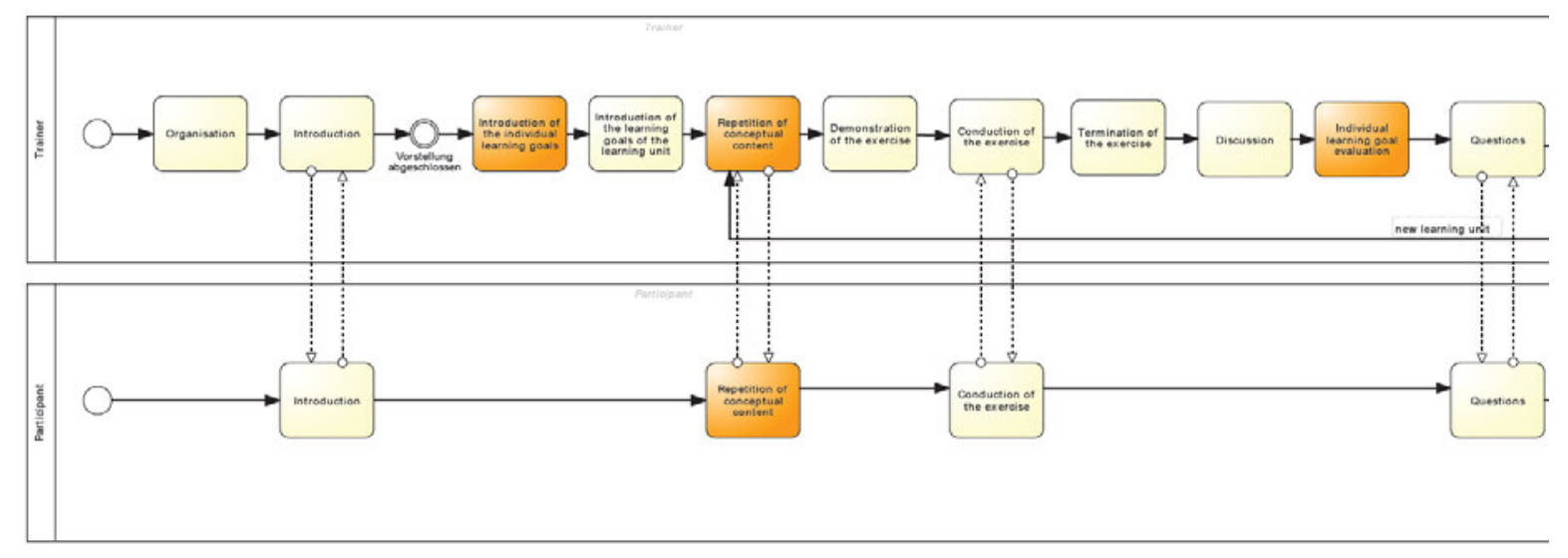

Fig. 2 Process excerpt of the face-to-face training

The yellow boxes depict the process components, derived within the case studies, the orange boxes were derived from the existing body of literature. Moreover, a detailed description and parameters for the customer-specific configuration of learning activities are included.

\section{OUTLOOK AND EXPECTED CONTRIBUTION}

In the next step, the derived productivity-optimized reference model will be evaluated, in accordance with Ahlemann and Riempp (2008), by means of expert workshops and the quantitative evaluation of the reference model within training sessions at a selected software training provider.

The expected contribution to theory comprises an empirically validated reference model for the productivity-optimized TMLS delivery in the context of trainings for software applications. Thereby the existing research gap of weaknesses in the systematic, theory-based delivery of TMLS is addressed. The expected contribution to practice comprises a reference model which enables software-training providers to design productivity-optimized TMLS.

\section{LITERATURE}

AES. (2010) Weiterbildungsverhalten in Deutschland.

Ahlemann, F., and Riempp, G. (2008) Refmod: A Conceptual Reference Model for Project Management Information Systems, Wirtschaftsinformatik 50(2): 88-97.

Alavi, M., and Leidner, D.E. (2001) Review: Knowledge Management and Knowledge Management Systems: Conceptual Foundations and Research Issues, MIS quarterly): 107-136. 
Arthur Jr, W., Bennett Jr, W., Edens, P.S., and Bell, S.T. (2003) Effectiveness of Training in Organizations: A Meta-Analysis of Design and Evaluation Features, Journal of Applied Psychology 88(2): 234.

Becker, J., and Schütte, R. (1996) Handelsinformationssysteme Verl. Moderne Industrie.

Bitzer, P., Bittner, E.A., and Leimeister, J.M. (2011) Identifying a Set of Relevant Input and Output Factors for a Knowledge Intensive Service within a Productivity Model for Educational Services, Hamburg, Germany

Bitzer, P., Wegener, R., and Leimeister, J.M. (2010) Entwicklung Eines Produktivitätsmodells Zur Systematisierung Von Lerndienstleistungen, Leipzig, Germany:

Compeau, D.R., and Higgins, C.A. (1995) Application of Social Cognitive Theory to Training for Computer Skills, Information Systems Research 6(2): 118-143.

Fitzsimmons, J.A., and Fitzsimmons, M.J. (2006) Service Management: Operations, Strategy, and Information Technology McGraw-Hill New York.

Garrison, D.R., and Kanuka, H. (2004) Blended Learning: Uncovering Its Transformative Potential in Higher Education, The Internet and Higher Education 7(2): 95-105.

Grönroos, C., and Ojasalo, K. (2004) Service Productivity: Towards a Conceptualization of the Transformation of Inputs into Economic Results in Services, Journal of Business Research 57(4): 414-423.

Gupta, S., and Bostrom, R.P. (2009) Technology-Mediated Learning: A Comprehensive Theoretical Model, Journal of the Association for Information Systems 10(9): 686-714.

Gupta, S., Bostrom, R.P., and Huber, M. (2008) End-User Training Methods: What We Know, Need to Know, ACM SIGMIS Database 41(4): 9-39.

Hevner, A., R., , March, S., T., Park, J., and Ram, S. (2004) Design Science in Information Systems Research, MIS Quarterly 28(1): 75-105.

Lehtinen, E., Hakkarainen, K., Lipponen, L., Rahikainen, M., and Muukkonen, H. (1999) Computer Supported Collaborative Learning: A Review, The JHGI Giesbers reports on education 10).

MBB. (2011) Weiterbildung Und Digitales Lernen Heute Und in Drei Jahren: Mobile Und Vernetzte Szenarien Im Aufwind).

McLaughlin, C.P., and Coffey, S. (1990) Measuring Productivity in Services, International Journal of Service Industry Management 1(1): 46-64.

Meise, V. (2001) Ordnungsrahmen Zur Prozessorientierten Organisationsgestaltung Kovač.

Parasuraman, A. (2002) Service Quality and Productivity: A Synergistic Perspective, Managing Service Quality 12(1): 6-9.

Sasidharan, S., and Santhanam, R. (2006) Technology-Based Training, Human-computer interaction and management information systems: applications 6): 247.

Schlagheck, B. (2000) Objektorientierte Referenzmodelle Für Das Prozess-Und Projektcontrolling Dt. Univ.-Verlag.

Schön, D.A. (1984) The Reflective Practitioner: How Professionals Think in Action Basic Books.

Simon, H.A. (1996) The Sciences of the Artificial the MIT Press.

Singh, H. (2003) Building Effective Blended Learning Programs, EDUCATIONAL TECHNOLOGYSADDLE BROOK THEN ENGLEWOOD CLIFFS NJ- 43(6): 51-54.

Takeda, H., Veerkamp, P., and Yoshikawa, H. (1990) Modeling Design Process, AI magazine 11(4): 37.

Wainhouse, R. 2007. "The Distance Education and E-Learning Landscape_-Volume 1: Learning Management Platforms, Software and Tools." Retrieved 25.09.2012, from http://www.wainhouse.com/images/reports/wrdistedelearnv1.pdf

Yin, R.K. (2009) Case Study Research: Design and Methods Sage publications, INC. 